\title{
AEST
}

10 years ESJ

Special edition

\section{Régénération assistée du karité (Vitellaria paradoxa C. F. Gaertn.) dans les parcs agroforestiers au Burkina Faso}

\section{Yempabou Hermann Ouoba,}

Université Nazi BONI / Unité de Formation et de Recherche en sciences et

Techniques, Bobo-Dioulasso, Burkina Faso

\section{Brigitte Bastide,}

Centre National de la Recherche Scientifique et Technologique, INERA / DEF,

Station de Farako Bâ, Bobo-Dioulasso, Burkina Faso

\section{Pascaline Coulibaly-Lingani,}

Centre National de la Recherche Scientifique et Technologique,INERA / DEF,

Ouagadougou, Burkina Faso

Sibiry Albert Kaboré,

Université Thomas Sankara / Centre universitaire de Tenkodogo

Sylvie Christiane Yaméogo-Gaméné,

Bassirou Belem,

Centre National de Semences Forestières, Ouagadougou, Burkina Faso

Souleymane Ganaba,

Centre National de la Recherche Scientifique et Technologique INERA / DEF, Ouagadougou, Burkina Faso

Paulin Ouoba,

Université Nazi BONI / Unité de Formation et de Recherche en sciences et

Techniques, Bobo-Dioulasso, Burkina Faso

\section{Joseph Issaka Boussim,}

Université Ouaga1 Joseph KI-Zerbo, Unité de Formation et de Recherche en

Sciences de la Vie et de la Terre, Ouagadougou, Burkina Faso

Submitted: 01 October 2020

Accepted : 02 November 2020

Published: 31 December 2020

Corresponding author:

Yempabou Hermann Ouoba

DOI: $10.19044 /$ esj.2020.v16n40p23

(c) Copyright 2020 Ouoba Y H et al..

Distributed under Creative Commons

BY-NC-ND 4.0 OPEN ACCESS

Cite as:

Ouoba Y. H. et al. (2020). Régénération assistée du karité (Vitellaria paradoxa C. F. Gaertn.) dans les parcs agroforestiers au Burkina Faso European Scientific Journal, ESJ, 16(40), 23. https://doi.org/10.19044/esj.2020.v16n40p23 


\section{Résumé}

Le karité (Vitellaria paradoxa C. F. Gaertn.) présente une importance sociale, culturelle, économique et alimentaire pour le Burkina Faso où il occupe la quatrième place dans les produits d'exportation. La pérennité de cette espèce dont les populations rurales sont tributaires, est compromise par de multiples phénomènes dont le manque de régénération, les pratiques culturales et la coupe abusive $d u$ bois pour satisfaire les besoins énergétiques. L'objectif de cette étude est de proposer des méthodes adéquates pour rajeunir les parcs à karité au Burkina Faso. Cinq sites de recherche ont été choisis suivant un gradient phytogéographique : Sobaka, Noumoudara et Kakoumana (secteur sud soudanien), Gonsé (secteur nord soudanien) et Bouria (secteur sub sahélien). Les essais effectués dans chaque parcelle choisie, ont comporté trois répétitions et 7 traitements, représentés par les différentes techniques de régénération (plantation, transplantation, semis direct libre, semis dans les buissons, régénération naturelle assistéeRNA-, induction de drageon, induction de pousse adventive). Les résultats indiquent que le taux de survie de la régénération naturelle assistée est audessus de $70 \%$ après deux années de suivi. Les plantations et les semis directs dans les buissons sont aussi des techniques efficaces pour la régénération/restauration des parcs à karité, avec respectivement des taux de survie de $13,33 \%$ et $6,67 \%$ dans le secteur sub sahélien, $12,22 \%$ et $6 \%$ dans le nord soudanien, et $55,56 \%$ et $25,33 \%$ dans le sud soudanien après la troisième année de suivi. En conclusion, la régénération assistée est la technique la plus efficiente pour restaurer les parcs à karité.

Mots-clés : karité, gestion des parcs agroforestiers, techniques de régénération, secteurs phytogéographiques, Burkina Faso. 


\section{Shea tree (Vitellaria paradoxa C. F. Gaertn.) assisted regeneration in Burkina Faso parklands}

\section{Yempabou Hermann Ouoba,}

Université Nazi BONI / Unité de Formation et de Recherche en sciences et

Techniques, Bobo-Dioulasso, Burkina Faso

\section{Brigitte Bastide,}

Centre National de la Recherche Scientifique et Technologique, INERA / DEF,

Station de Farako Bâ, Bobo-Dioulasso, Burkina Faso

\section{Pascaline Coulibaly-Lingani,}

Centre National de la Recherche Scientifique et Technologique,INERA / DEF, Ouagadougou, Burkina Faso

Sibiry Albert Kaboré,

Université Thomas Sankara / Centre universitaire de Tenkodogo

Sylvie Christiane Yaméogo-Gaméné, Bassirou Belem,

Centre National de Semences Forestières, Ouagadougou, Burkina Faso

Souleymane Ganaba,

Centre National de la Recherche Scientifique et Technologique INERA / DEF, Ouagadougou, Burkina Faso

Paulin Ouoba,

Université Nazi BONI / Unité de Formation et de Recherche en sciences et

Techniques, Bobo-Dioulasso, Burkina Faso

\section{Joseph Issaka Boussim,}

Université Ouaga1 Joseph KI-Zerbo, Unité de Formation et de Recherche en

Sciences de la Vie et de la Terre, Ouagadougou, Burkina Faso

\section{Abstract}

The Shea (Vitellaria paradoxa C. F. Gaertn.) is of enormous social, cultural, economic and nutritional importance for Burkina Faso where it ranks fourth in exports. The sustainability of this species on which rural populations depend is compromised by multiple phenomena, including the lack of regeneration of shea tree and the abusive cutting of wood to meet energy needs. This work aimed to propose adequate methods for rejuvenating shea parkland in Burkina Faso. Five sites distributed along a phytogeographic gradient were selected for tests : Sobaka, Noumoudara and Kakoumana (South-Sudanian phytogeographic zone), Gonsé (NorthSudanian phytogeographic zone) and Bouria (sub-Sahelian phytogeographic zone). The field trials included three repetitions by regeneration technique (planting, transplanting, direct sowing free, sowing in bushes and assisted natural regeneration -ANR-, sucker induction, induction of adventitious growth). The results indicate that the survival rate of assisted natural 
regeneration is above $70 \%$ after two years of follow-up. Planting and direct seeding in bushes are also effective techniques for the regeneration / restoration of shea tree parks with respectively survival rates of $13.33 \%$ and $6.67 \%$ in the sub sahelian sector, $12.22 \%$ and $6 \%$ in north sudanian, and $55.56 \%$ and $25.33 \%$ in south sudanian, after the third year of monitoring. In conclusion, in order to restore the shea parks, all seedlings regardless of their origins, will need to be assisted in.

Keywords: shea tree, parkland management, regeneration technics, phytogeographical sectors, Burkina Faso

\section{Introduction}

Le Burkina Faso est un pays dans lequel $72,1 \%$ de la population résident en milieu rural (Burkina Faso, 2016), et dépendent d'une agriculture de subsistance (INSD, 2018). Chaque année, les ménages ruraux connaissent une période de soudure alimentaire qui survient en début de saison des pluies et s'étend jusqu'aux nouvelles récoltes. Durant cette période, les populations ont recours aux plantes à feuilles, fruits, fleurs ou tubercules comestibles pour la satisfaction de leurs besoins alimentaires dont le karité (Ganaba et al., 2002 ; Thiombiano et al., 2010). De par sa dominance dans les parcs agroforestiers avec des proportions pouvant atteindre $80 \%$ des arbres conservés et la valeur socio-économique des ses fruits, le karité figure parmi les principales espèces pourvoyeuses de pfnl au Burkina Faso (Boffa, 1999 ; APFNL, 2012). Les activités liées aux seuls fruits de l'arbre à karité ont généré environ 28,9 milliards de francs CFA en 2011 (Burkina Faso, 2016).

Malgré le fait, que le karité soit protégé par le Code forestier du Burkina Faso (Assemblée Nationale, 2011), l'arbre continue à être exploité pour son bois, et ses peuplements souffrent de l'empiétement croissant des exploitations agricoles. En effet, les études récentes indiquent que l'espèce est vulnérable face à des menaces sévères liées aux activités humaines et au changement climatique (Boffa, 2015 ; Gaisberger et al., 2017 ; Ouédraogo et al., 2017) et les peuplements naturels vieillissent (Kaboré et al., 2012). Les problèmes liés au vieillissement des parcs à karité incluent les coupes des arbres adultes pour les besoins énergétiques des populations, la lenteur de la croissance de l'espèce et le manque d'entretien des jeunes plants.

Les techniques de multiplication utilisées pour la reproduction $\mathrm{du}$ karité sont les semis en pots suivis de plantation, les semis directs au sol, le greffage (Sanou et al., 2004) et le marcottage (Raebild et al., 2011a). Selon Belem et al. (2008), la régénération artificielle des espèces forestières se fait principalement à travers le semis ou la plantation en saison de pluie. Ceci requiert l'obtention de semences, l'installation de pépinières, de nombreux achats (sachets, terre, sable...) et l'entretien des plantules qui se révèlent être 
trop coûteux pour le producteur. En relation avec les semis suivis de plantation du karité, Dianda et al. (2010) notent de nombreuses contraintes parmi lesquelles la lenteur de la croissance juvénile de la plante, la longueur de son cycle végétatif, mais aussi le manque quasi-général de connaissances concernant la sylviculture de l'arbre. En plus, les jeunes karités doivent rester en pépinière pendant au moins un an avant d'être transplantés, et ils ne deviendront reproducteurs qu'au-delà de la vingtième année s'ils sont protégés des animaux et bien entretenues (Sallé et al., 1991).

Ayant montré que le karité prolifère abondamment dans les exploitations agricoles, mais ne survivent pratiquement pas du fait des pratiques agricoles inappropriées, et de la courte durée des jachères qui n'atteignent pas 15 ans, Kaboré et al. (2012) recommande la préservation de quelques plantules dans les champs et leur entretien afin d'amorcer le rajeunissement des parcs.

Compte tenu de la conjoncture économique pour la conservation des forêts tropicales et la restauration des zones boisées dégradées, assister la régénération naturelle parait être l'option la plus fiable (Hardwick et al., 1997 ; Honu et Dang, 2002) dans la mesure où la densification d'un peuplement arboré doit être envisagée en fonction des pratiques paysannes, afin d'optimiser l'adéquation entre les activités agricoles et les usages de la ressource arborée (Peltier et al., 2007).

La régénération naturelle assistée (RNA) est une pratique qui consiste à protéger et à gérer les jeunes arbres jusqu'à ce qu'ils se développent pour s'intégrer dans l'espace agricole. Elle se distingue du reboisement ou la plantation d'arbres comme, les brise-vents, et les peuplements naturels dans les massifs forestiers. Cette pratique qui s'applique dans un espace boisé ou dégradé est assez documentée (Lawali et al., 2018 ; Belem et al., 2017 ; Baggnian et al., 2013 ; Botoni et al., 2010 ; Lafleur, 2008 ; Shono et al., 2007 ; Larwanou et al., 2006 ; Marou Zarafi et al., 2002). Dans le but de guider les agents de développement et les producteurs pour appliquer la RNA à l'échelle des espèces individuelles, des informations techniques font défaut.

Pour le cas du karité, il s'avère que la distribution spatiale des plantules de karité qui s'établissent spontanément dans les champs, n'est souvent pas favorable à l'implantation d'un futur arbre du fait que la plupart des juvéniles sont situés sous le houppier des semenciers (Thiombiano et al., 2010 ; Kaboré et al., 2012) ; ce qui nécessite une intervention humaine pour orienter la distribution des jeunes pieds qui seront assistés par la suite.

L'objectif de la présente étude est à la comparaison de sept techniques de régénération du karité afin de sélectionner les plus appropriées suivant secteurs phytogéographiques du Burkina Faso. L'hypothèse de 
recherche examinée dans cette activité serait que la RNA est la technique la plus efficiente pour la régénération du karité.

\section{Matériel et méthodes}

\section{Sites d'étude}

Le choix des sites d'étude a été effectué en fonction du secteur phytogéographique dans l'aire de répartition du karité au Burkina Faso et des zones ciblées par le plan de mise en œuvre du projet Fond Compétitif National / Programme de Productivité Agricole en Afrique de l'Ouest (FCN/PPAAO) dénommé : «Valorisation en milieu paysan des acquis de la recherche pour lutter contre la dégradation et le vieillissement des peuplements de karités en fonction de la zone climatique au Burkina Faso » (Figure 1).
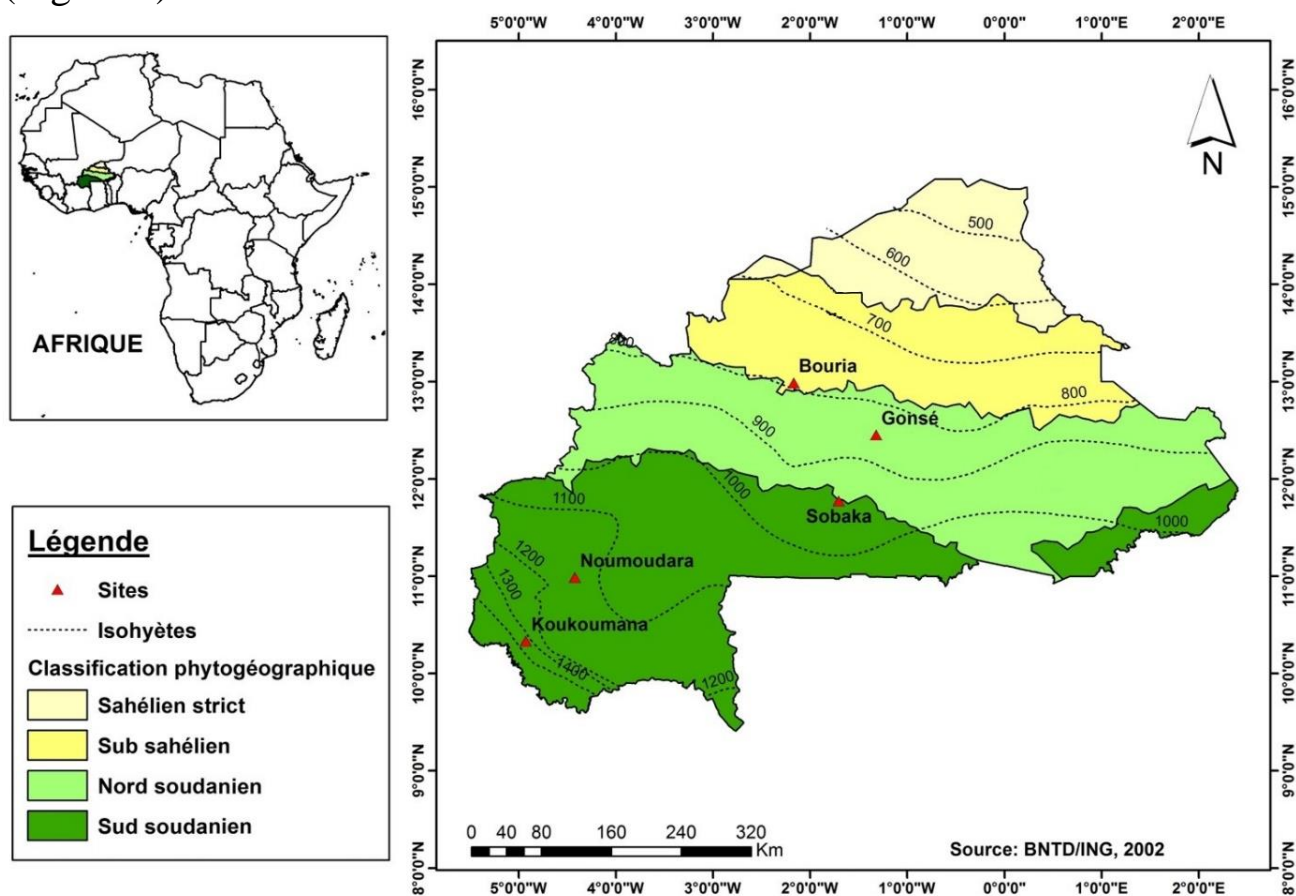

Figure 1. Carte phytogéographique du Burkina Faso indiquant les sites d'étude (Source : BNDT/ING, 2002)

Les sites d'étude couvrent ainsi 5 localités qui sont Bouria, Gonsé, Sobaka, Noumoudara et Kakoumana (Tableau 1).

Tableau 1. Quelques caractéristiques des sites d'étude

\begin{tabular}{llll}
\hline Sites d'étude & Situation administrative & $\begin{array}{l}\text { Pluviométrie moyenne } \\
\text { annuelle }(\mathbf{m m})\end{array}$ & $\begin{array}{l}\text { Principales } \\
\text { cultures }\end{array}$ \\
\hline Bouria & $\begin{array}{l}\text { Commune de Yako } \\
\text { Province du Passoré }\end{array}$ & $\mathbf{7 4 9 \pm 1 3 8}$ & $\begin{array}{l}\text { Niébé/Sorgho } \\
\text { blanc }\end{array}$ \\
& $\begin{array}{l}\text { Région du Nord } \\
\text { Gommune de Saaba }\end{array}$ & $\mathbf{7 5 6} \pm \mathbf{1 1 2}$ & Niébé/Sorgho
\end{tabular}




\begin{tabular}{|c|c|c|c|}
\hline & $\begin{array}{l}\text { Province du Kadiogo } \\
\text { Région du Centre }\end{array}$ & & blanc \\
\hline Sobaka & $\begin{array}{l}\text { Commune de Sapouy } \\
\text { Province du Ziro } \\
\text { Région du Centre-Ouest }\end{array}$ & $903 \pm 129$ & $\begin{array}{l}\text { Niébé/Sorgho } \\
\text { blanc }\end{array}$ \\
\hline Noumoudara & $\begin{array}{l}\text { Commune de Péni } \\
\text { Province du Houet } \\
\text { Région des Hauts-Bassins }\end{array}$ & $1029 \pm 170$ & Maïs/Niébé \\
\hline Kakoumana & $\begin{array}{l}\text { Commune de Niangoloko } \\
\text { Province de la Comoé } \\
\text { Région des Cascades }\end{array}$ & $1150 \pm 165$ & Maïs/Niébé \\
\hline
\end{tabular}

Dans toutes ces localités, l'agriculture est l'activité la plus pratiquée et les arbres utilitaires incluant le karité, le néré et le tamarinier; sont délibérément préservés dans les exploitations agricoles.

\section{Matériel végétal}

Appartenant à la famille des Sapotaceae, le karité est une espèce végétale autochtone des savanes soudaniennes et soudano guinéennes de l'Afrique subsaharienne où il imprime une physionomie au paysage (Thiombiano et al., 2016). Au Burkina Faso, Bondé (2019) estime le potentiel démographique du karité à 178718 641,79 individus adultes repartis sur une superficie de 20819109,09 ha. Naughton et al. (2015) estiment qu'il y'a environ 1,84 milliards de karité sur l'ensemble de l'aire de distribution de l'espèce. L'importance de la densité du karité est indubitablement liée aux multiples biens et services qu'il fournit aux populations qui, parfois entretiennent des parcs quasi monospécifiques (Photo 1).

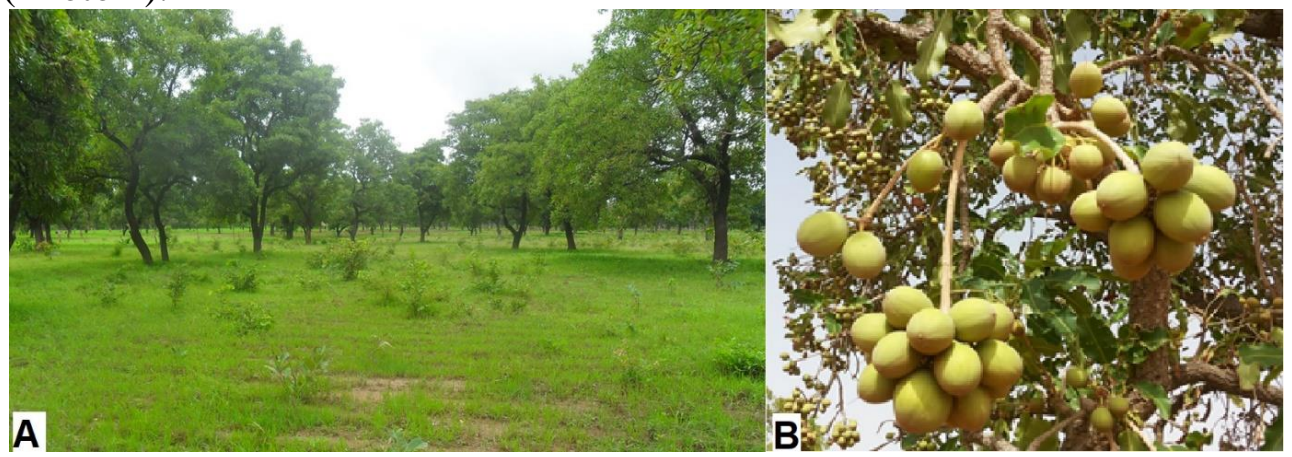

Photo 1. (A) Parc à karité et (B) Infrutescences de karité. (Photos Ouoba Y.H., 2013)

\section{Echantillonnage et collecte des données}

Sept techniques de régénération ont été testées chacune dans trois champs par site, à savoir le semis direct libre, le semis direct dans des buissons, la plantation, la transplantation de sauvageons, la stimulation du 
drageonnage, l'induction de pousses adventives et la RNA. Les essais ont été installés en début de la saison pluvieuse.

- Pour le semis direct libre, deux (2) graines fraiches ont été semées par poquet pour augmenter les chances d'obtenir au moins une plantule par poquet (photo 2 (A)). Les poquets ont été au nombre de 300 par site.

- Le semis direct dans les buissons est considéré comme une amélioration du semis direct libre (photo 2 (B)). Ainsi, 150 poquets ont été réalisés sous des espèces buissonnantes représentatives de chaque site ou des touffes d'Andropogon gayanus Kunth. Dans chaque poquet, 2 graines fraiches ont été semées.

- La plantation : elle a porté sur 90 karités par site. Les plantules provenaient d'amandes fraiches de karité collectées à Sobaka, semées dans des pots et entretenues en pépinière pendant un an (photo 2 (C)). Les trous de plantation ont été de $60 \mathrm{~cm}$ profondeur et $60 \mathrm{~cm}$ diamètre.

- La transplantation de sauvageons : des plantules ayant poussé dans un endroit où elles ne peuvent se développer (formation naturelle, sous un houppier) ont été déracinées et transplantées dans des champs. Ces plantules ont été extraites à l'aide d'un cylindre métallique d'environ $30 \mathrm{~cm}$ de diamètre et $70 \mathrm{~cm}$ de hauteur puis mises dans des pots de pépinière (photo 2 (D)). Après 7 jours d'observation, les plantules vigoureuses ont été plantées à raison de 150 plantules. Toutes les plantules ont été positionnées avec un écartement d'environ $10 \mathrm{~m}$ par rapport aux autres individus de karité, qu'il s'agisse d'autres plantules et ou d'autres adultes, pour ne pas entraver la culture mécanisée et/ou réduire les rendements céréaliers du fait d'une forte densité d'arbres dans la parcelle. 


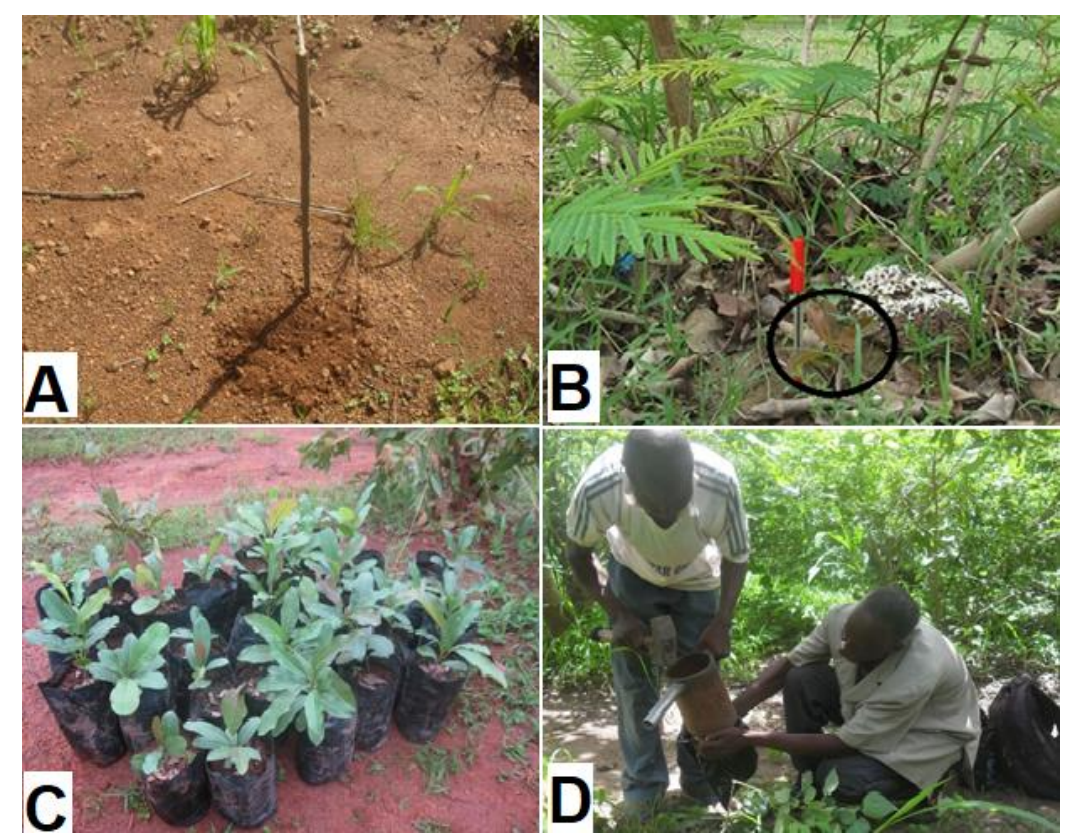

Photo 2. Différentes techniques de régénération du karité. (A) Poquet de semis direct libre matérialisé par un piquet, (B) plantule d'un an issu d'un semis direct dans un buisson de Acacia macrostachya Reichenb. ex Benth., (C) plantules âgées d'un an destinées à la plantation et (D) extraction d'un sauvageon pour la transplantation.(Photos Ouoba Y.H., 2013)

- Pour la stimulation de drageonnage, des inventaires ont été menés dans 9 champs à Gonsé et ont permis de recenser 3 classes de diamètre dans lesquelles se retrouvent $97 \%$ des pieds de karité. Il s'agit des classes de $] 25 \mathrm{~cm} ; 35 \mathrm{~cm}]$, de $] 35 \mathrm{~cm} ; 45 \mathrm{~cm}]$ et de $] 45 \mathrm{~cm}$ ; $55 \mathrm{~cm}$ ]. Dans chaque site, 18 pieds de karité répartis équitablement dans les trois classes ci-dessus citées, ont étés sélectionnés pour les tests d'induction des drageons et des pousses adventives. La stimulation de drageonnage a consisté à effectuer 15 ruptures et 15 scarifications sur les racines de chaque arbre. Ces différentes manipulations ont été positionnées équitablement sur trois cercles concentriques au pied de chaque arbre, sur les périmètres situés respectivement à 3,6 et $9 \mathrm{~m}$ de l'arbre mère (photo $3(\mathrm{~A})$ ). Les trous effectués pour atteindre les racines n'ont pas été rebouchés (Belem $e t$ $a l ., 2008$ ) et les racines manipulées sont restées ainsi à l'air libre et à la lumière durant plusieurs jours avant d'être recouvertes progressivement et naturellement par la terre et les débris organiques.

- L'essai d'induction de pousses adventives a porté sur des individus de karité choisis selon les critères similaires à ceux de l'essai 
d'induction de drageons. Ainsi, 10 scarifications ont été effectuées au niveau de la base du fût de chaque karité (photo 3 (B)).

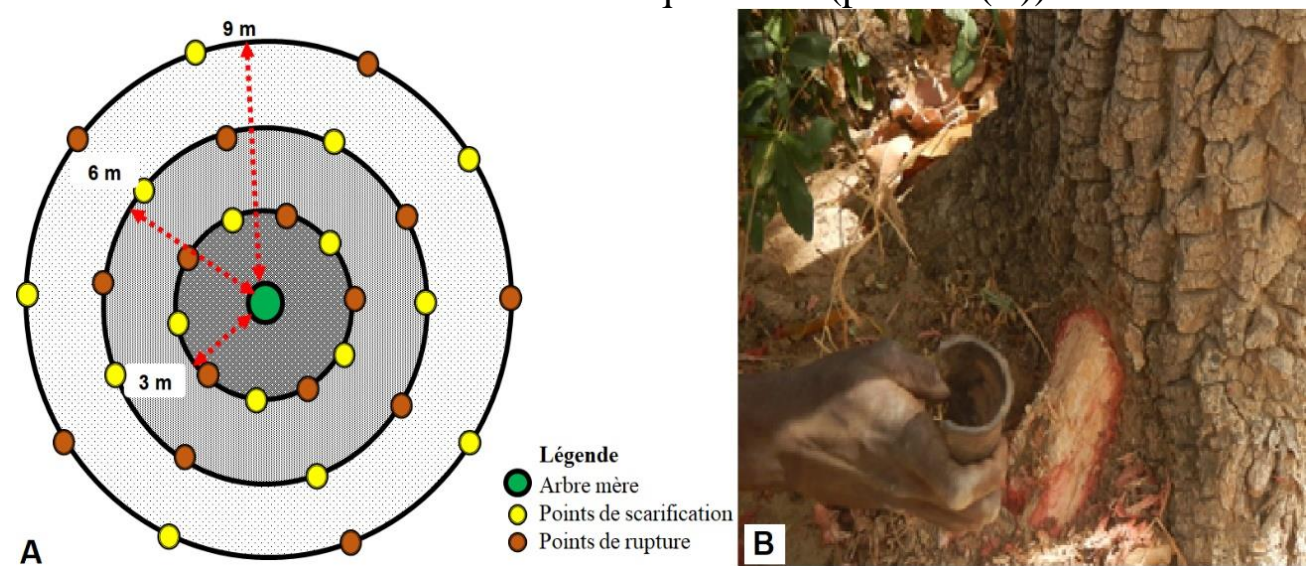

Photo 3. (A) Dispositif théorique pour la stimulation de drageonnage et (B) stimulation de pousses adventives par scarification. (Photo Ouoba Y.H., 2014)

Dans le cadre de la RNA, trois (03) traitements ont été testés, chacun comportant trente (30) plantules spontanées par parcelle, soient au total 90 plantules appartenant à chaque traitement par site. Le premier traitement a été constitué par les témoins (photo $4(\mathrm{~A})$ ) ; le second par les plantules protégées uniquement contre le bétail par une barrière d'épines tressées (photo 4 (B)) ; le troisième par les plantules protégées contre le bétail par une barrière d'épines tressées et arrosées à raison de 101 d'eau/plantule tous les trois (03) jours. Les dispositifs ont été maintenus arrosés durant la saison sèche d'octobre 2014 à mai 2015 puis d'octobre 2015 à mai 2016; les barrières d'épines étant confectionnées à partir de branches mortes.

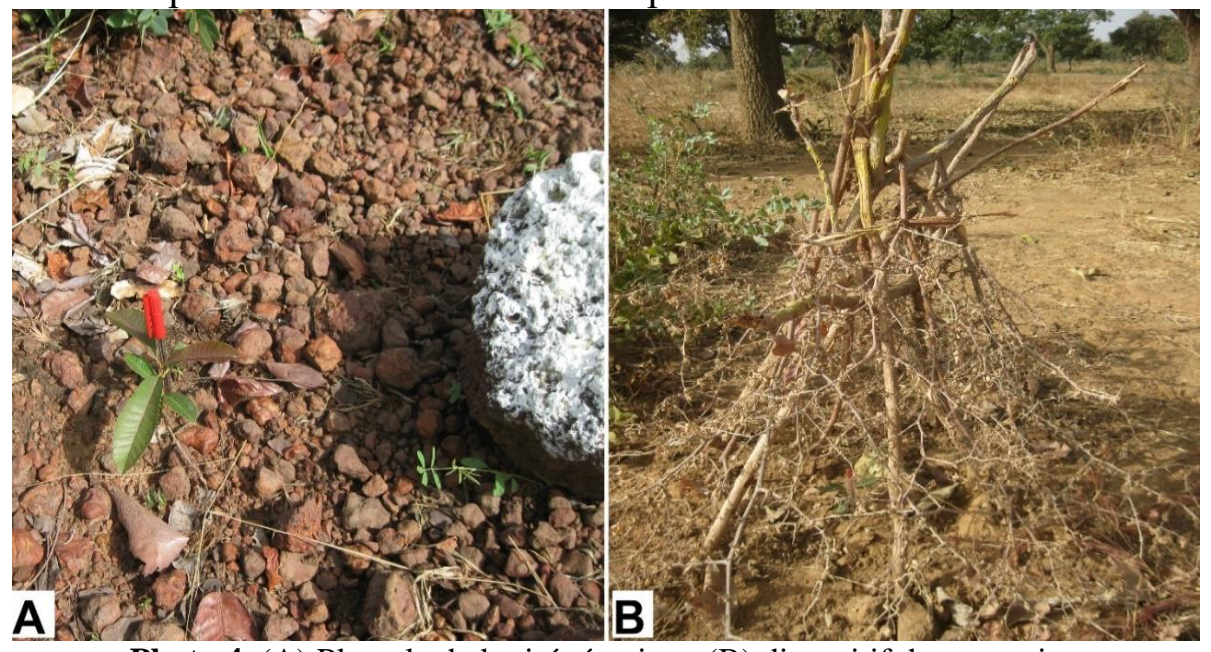

Photo 4. (A) Plantule de karité témoin et (B) dispositif de protection de plantule de karité. (Photos Ouoba Y.H., 2014) 
Les coordonnées géographiques de tous les individus adultes (toutes les espèces ligneuses confondues) et des pieds de karité introduits ont été relevées à l'aide d'un GPS dans chaque parcelle. Le positionnement de tous les ligneux adultes et des plants de karité utilisés pour enrichir un parc permet une exploitation rationnelle des parcelles agroforestières (Figure 2). L'emplacement de chaque plantule a été marqué par un caillou peint ou un piquet, pour permettre les suivis-évaluations annuels étalés sur 3 ans. Lors de ces activités, la vitalité, la hauteur, le diamètre au collet et le nombre de ses feuilles de chaque plantule ont été relevés. Les mêmes paramètres ont été notés lors de la mise en place de chaque essai. Les éventuels drageons et pousses adventives induits doivent être notés puis mesurés (hauteur et diamètre) avant l'observation de leur état sanitaire. Les données pour la RNA ont été collectées seulement au début de l'expérimentation, à la fin de la première année et à la fin de la seconde année.

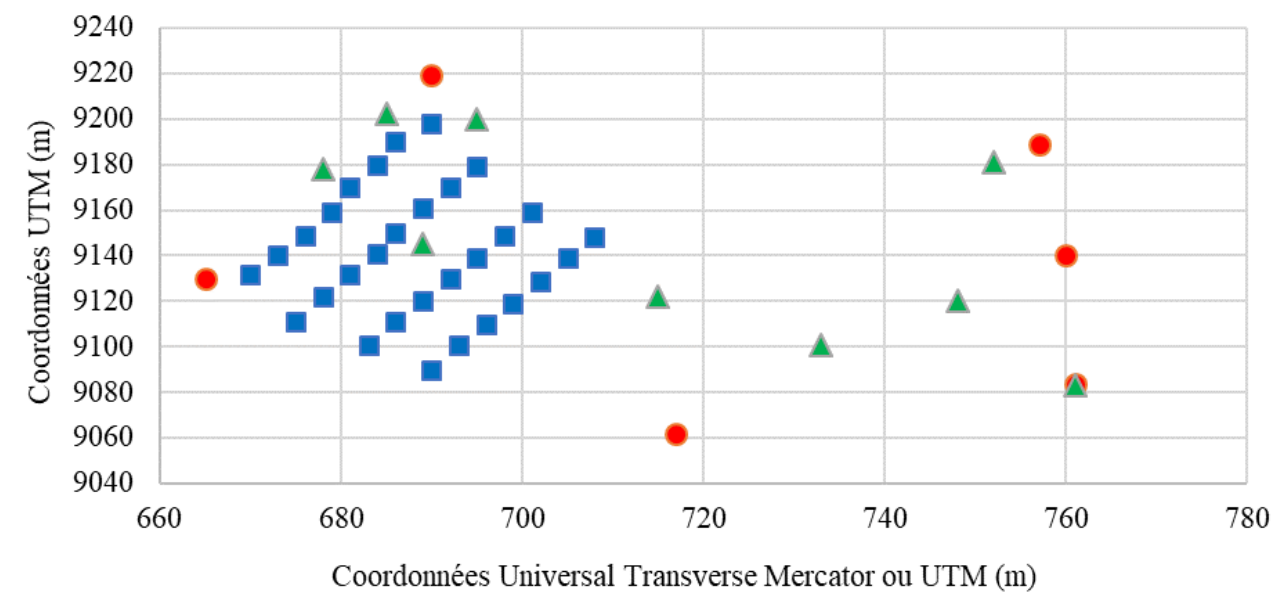

- Positionnement des plants $\bullet$ Limites de la parcelle $\Delta$ Ligneux adultes de la parcelle

Figure 2. Cartographie d'une parcelle de plantation à Bouria

\section{Traitement et analyse des données}

Une cartographie de chaque dispositif, permettant de représenter sur un graphique, la dynamique de l'occupation actuelle et future des ligneux dans le parc à karité a été effectuée à l'aide des coordonnées géographiques avec le tableur Microsoft Excel 2016. Le même tableur a servi pour le calcul des taux de survie ainsi que des valeurs moyennes de hauteur et de diamètre. Le taux de survie (TS) a été calculé pour chaque technique et traitement par la formule suivante :

\begin{tabular}{|l|l|}
\hline TS $=100 \times \frac{\mathrm{Na}-\mathrm{Nb}}{\mathrm{Na}}$ & $\begin{array}{l}N a \text { est le nombre de plantules de l'année « a » et } N b, \text { le } \\
\text { nombre de plantules vivantes en année « } \mathrm{a}+1 » .\end{array}$ \\
\hline
\end{tabular}


Le test exact de Fisher et des tests d'égalité de deux proportions ont été effectués pour comparer les taux de survie des plantules issues des différentes techniques entre les secteurs phytogéographiques. Le logiciel $\mathrm{R}$ version 3.6.2 a été utilisé pour les différents tests de comparaison.

\section{Résultats}

\section{Induction de drageonnage et de pousses adventives}

A l'issu des suivis-évaluations des dispositifs, aucun drageon ni pousse adventive n'ont été relevés. La méthodologie adoptée dans cette étude n'a donc pas permis de reproduire le karité par drageonnage ou par rejet.

Taux de survie des plantules issues de la plantation, du semis direct dans les buissons, du semis direct libre et de la transplantation

La plantation est la plus efficace des 4 techniques avec un taux de survie qui décroît du secteur sud soudanien (55,56\%), au secteur sub sahélien $(13,33 \%)$ et au secteur nord soudanien $(12,22 \%)$. Les semis directs dans les buissons ont fourni des taux de survie inférieurs à ceux des plantations, soit de façon décroissante, $25,33 \%$ dans le secteur sud soudanien, 6,67\% dans le secteur sub sahélien et $6 \%$ dans le secteur nord soudanien. Les taux de survie des semis directs dans les buissons sont supérieurs à ceux des semis directs libres qui diminuent du secteur sud soudanien $(6,33 \%)$, au secteur nord soudanien $(4,33 \%)$ et au secteur sub sahélien (0,67\%). Les taux de survie des transplantations aussi décroissent du secteur sud soudanien (15,33\%), au secteur sub sahélien $(2,67 \%$ ) et au secteur nord soudanien -0,67\%- (Figure 3).

Dans l'ensemble, les taux de survie des différentes techniques varient significativement $(\mathrm{p}=0,024)$. Le secteur phytogéographique sud soudanien a présenté des taux de survie significativement supérieurs à ceux des deux autres secteurs pour la plantation $(55,56 \%)$, le semis direct dans les buissons $(25,33 \%)$ et la transplantation $(15,33 \%)$. Les taux de survie du semis direct libre du secteur sud soudanien ont été significativement supérieurs à ceux du secteur sub sahélien, mais pas à ceux du secteur nord soudanien. Les comparaisons montrent aussi que les taux de survie dans le secteur sub sahélien n'ont pas été significativement inférieurs à ceux dans le nord soudanien sauf pour les semis directs libres (Tableau 2). 

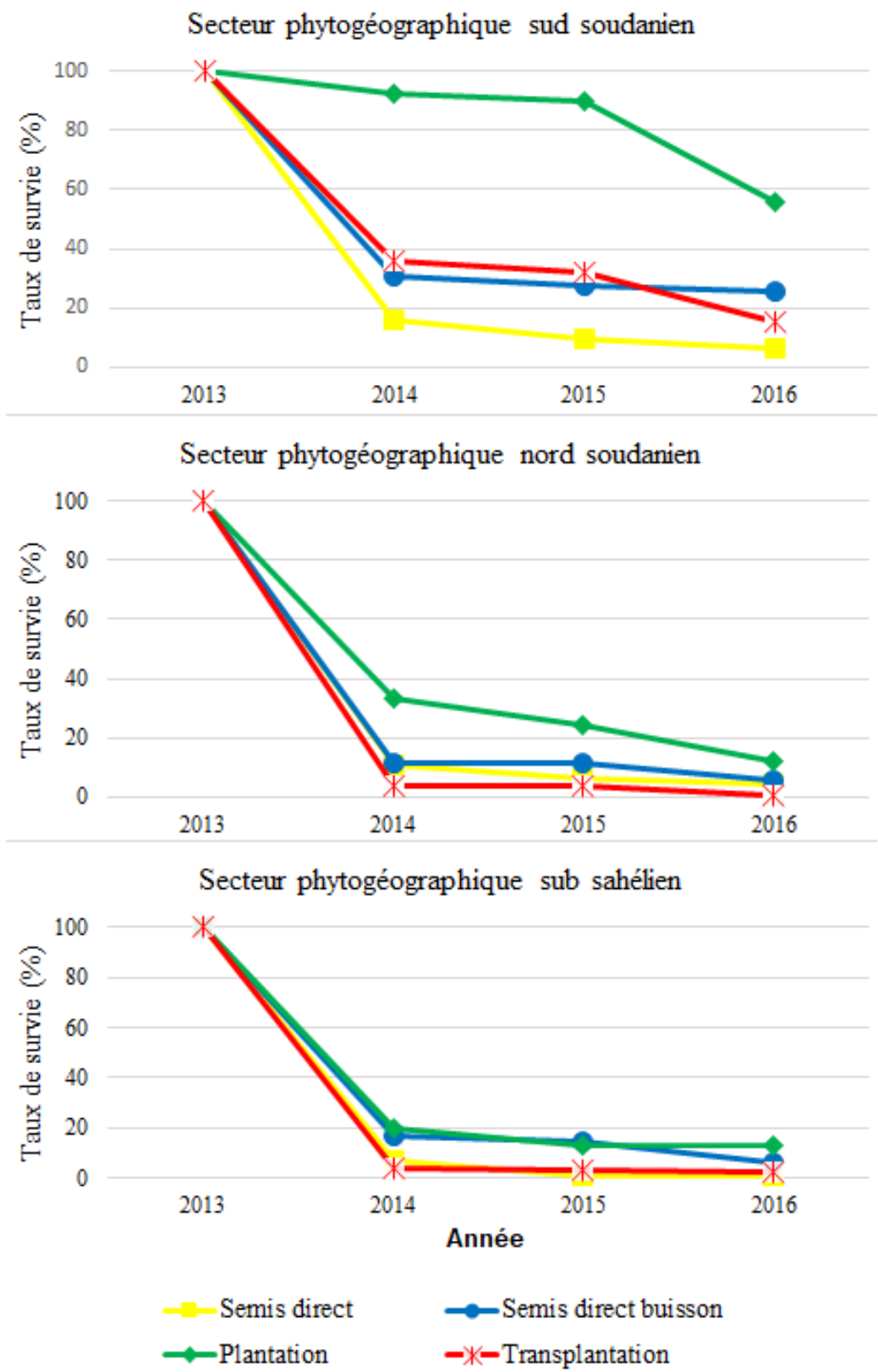

Figure 3. Taux de survie des plantules par technique et par secteur phytogéographique 
Tableau 2. Résultats des tests de comparaison des proportions des plantules

\begin{tabular}{|c|c|c|c|c|}
\hline $\begin{array}{l}\text { Secteur } \\
\text { phytogéographique }\end{array}$ & Plantation & $\begin{array}{l}\text { Semis } \\
\text { buisson }\end{array}$ & Semis direct & Transplantation \\
\hline $\begin{array}{l}\text { Sub sahélien < } \\
\text { Nord soudanien }\end{array}$ & $\begin{array}{l}X^{2}=0 ; d d l= \\
1 ; p=0,5\end{array}$ & $\begin{array}{l}X^{2}=0 ; d d l= \\
1 ; p=0,5\end{array}$ & $\begin{array}{l}X^{2}=6,838 \\
\text { ddl }=1 ; p= \\
0,004\end{array}$ & $\begin{array}{l}X^{2}=0,814 ; d d l= \\
1 ; p=0,816\end{array}$ \\
\hline $\begin{array}{l}\text { Sub sahélien }<\text { Sud } \\
\text { soudanien }\end{array}$ & $\begin{array}{l}X^{2}=33,682 \\
\text { ddl }=1 ; p< \\
0,001\end{array}$ & $\begin{array}{l}\mathrm{X}^{2}=18.08 \\
\mathrm{ddl}=1 ; \mathrm{p}< \\
0,001\end{array}$ & $\begin{array}{l}X^{2}=12,633 \\
\text { ddl }=1 ; p< \\
0,001\end{array}$ & $\begin{array}{l}X^{2}=13,187 ; \mathrm{ddl} \\
=1 ; \mathrm{p}<0,001\end{array}$ \\
\hline $\begin{array}{l}\text { Nord soudanien < } \\
\text { Sud soudanien }\end{array}$ & $\begin{array}{l}X^{2}=35,807 \\
\text { ddl }=1 ; p< \\
0,001\end{array}$ & $\begin{array}{l}X^{2}=19,78 ; \\
d d l=1 ; p< \\
0,001\end{array}$ & $\begin{array}{l}X^{2}=0,825 \\
d d l=1 ; p= \\
0,182\end{array}$ & $\begin{array}{l}X^{2}=19,973 ; \mathrm{ddl} \\
=1 ; p<0,001\end{array}$ \\
\hline
\end{tabular}

\section{Taux de survie des plantules soumises à la RNA}

Les taux de survie des plantules protégées et arrosées restent élevés quel que soit le secteur phytogéographique soient $(78,89 \%)$ dans le secteur sub sahélien, $(77,78 \%)$ dans le secteur sud soudanien et $(73,33 \%)$ dans le secteur nord soudanien. Dans le cas des plantules protégées uniquement, les taux de survie sont les plus élevés dans le secteur sud soudanien $(72,22 \%)$ et le secteur sub sahélien (72,22\%). Ces taux sont de 38,89\% dans le secteur nord soudanien. Pour ce qui est des témoins, les taux de survie varient de $66,67 \%$ dans le secteur sud soudanien, 23,33\% dans le secteur sub sahélien et $20 \%$ dans le secteur nord soudanien (Figure 4).

Les taux de survie des plantules protégées et arrosées ne varient pas significativement entre les secteurs phytogéographiques avec $X^{2}=0,26$ et $\mathrm{p}=0,87$. Par contre les taux de survie des plantules protégées uniquement ont baissé significativement du sud soudanien vers le sub sahélien avec $\mathrm{X}^{2}=8,50$ et $\mathrm{p}=0,014$. Il en est de même pour les taux de survie des témoins $\left(\mathrm{X}^{2}=8,26\right.$; $\mathrm{p}=0,016$ ).

Les variations ont été significatives entre les différents traitements en fonction des secteurs phytogéographiques $\left(X^{2}=41,90 ; p<0,0001\right)$. 

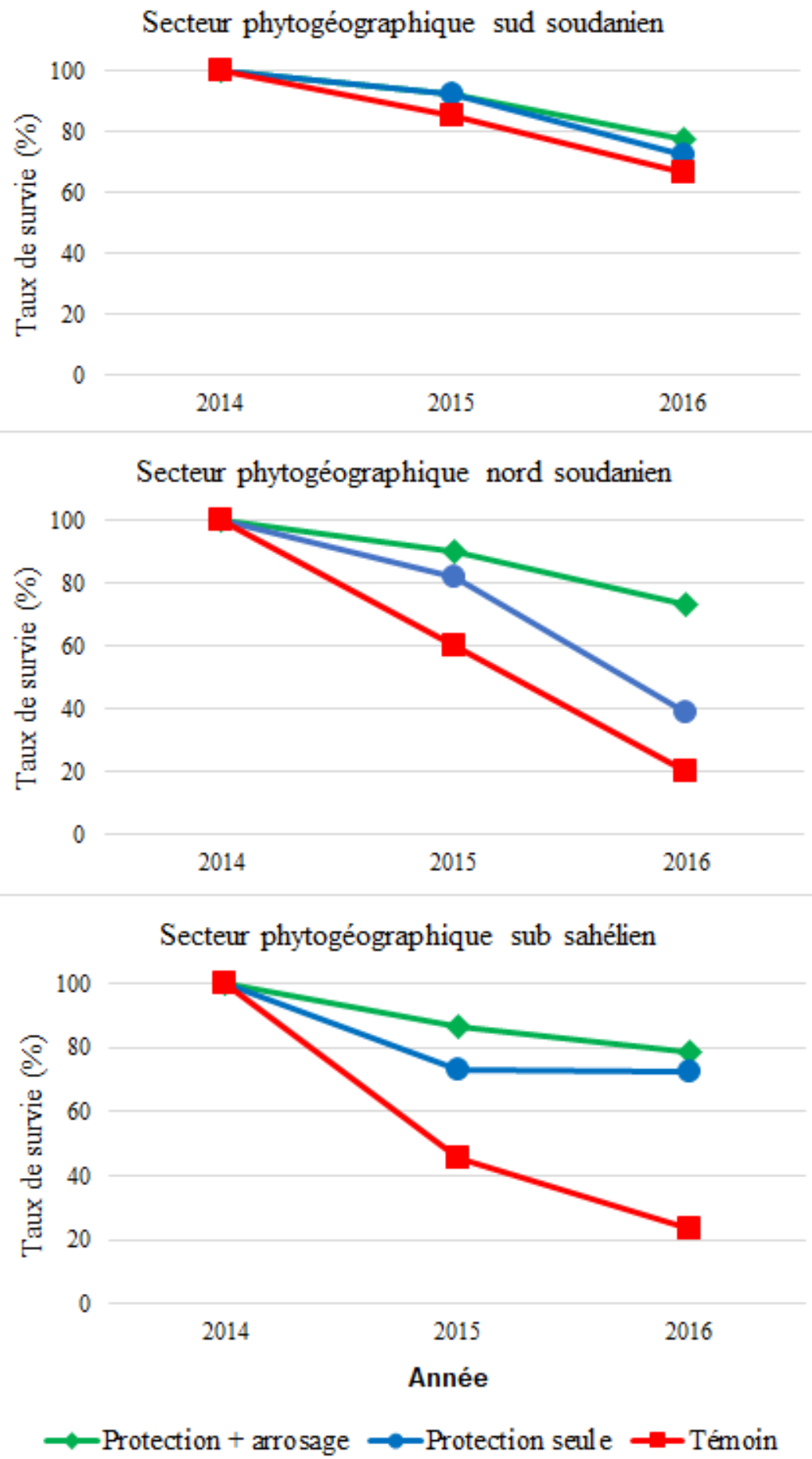

Figure 4. Taux de survie des plantules par traitement et par secteur phytogéographique 


\section{Croissance verticale des plantules issues de la plantation, du semis direct dans les buissons, du semis direct libre et de la transplantation}

A la fin de l'expérimentation, les transplants grandissent plus vite que les plantules issues des autres techniques soient de $3,98 \mathrm{~cm}$ dans le secteur sud soudanien, de $1,56 \mathrm{~cm}$ dans le secteur nord soudanien et de $1,05 \mathrm{~cm}$ dans le secteur sub sahélien. Les gains en hauteur des semis directs dans les buissons sont de $2,13 \mathrm{~cm}$ dans le secteur nord soudanien, $1,77 \mathrm{~cm}$ dans le secteur sub sahélien et de 1,34 cm dans le secteur sud soudanien. Dans le cas des semis directs libres, les augmentations de taille varient de $2,13 \mathrm{~cm}$ dans le secteur nord soudanien, $1,77 \mathrm{~cm}$ dans le secteur sub sahélien et $1,34 \mathrm{~cm}$ dans le secteur sud soudanien. Pour les plantules issues des plantations, les augmentations de taille varient de $0,53 \mathrm{~cm}$ dans le secteur nord soudanien, $0,18 \mathrm{~cm}$ dans le secteur sub sahélien et $0,11 \mathrm{~cm}$ dans le secteur sud soudanien. L'augmentation de la hauteur des plantules issues de la plantation reste faible par rapport à celle des plantules issues des autres techniques (figure 5).

Il n'y a pas de différences significatives entre les hauteurs des semis directs dans les buissons et celles des semis directs libres avec $X^{2}=0,025$ et $\mathrm{p}=0,98$. Il n'y a pas non plus de différence significative entre les hauteurs des plantules issues de transplantation et celles issues de plantation avec $\mathrm{X}^{2}=$ 10,89 et $\mathrm{p}=0,21$.

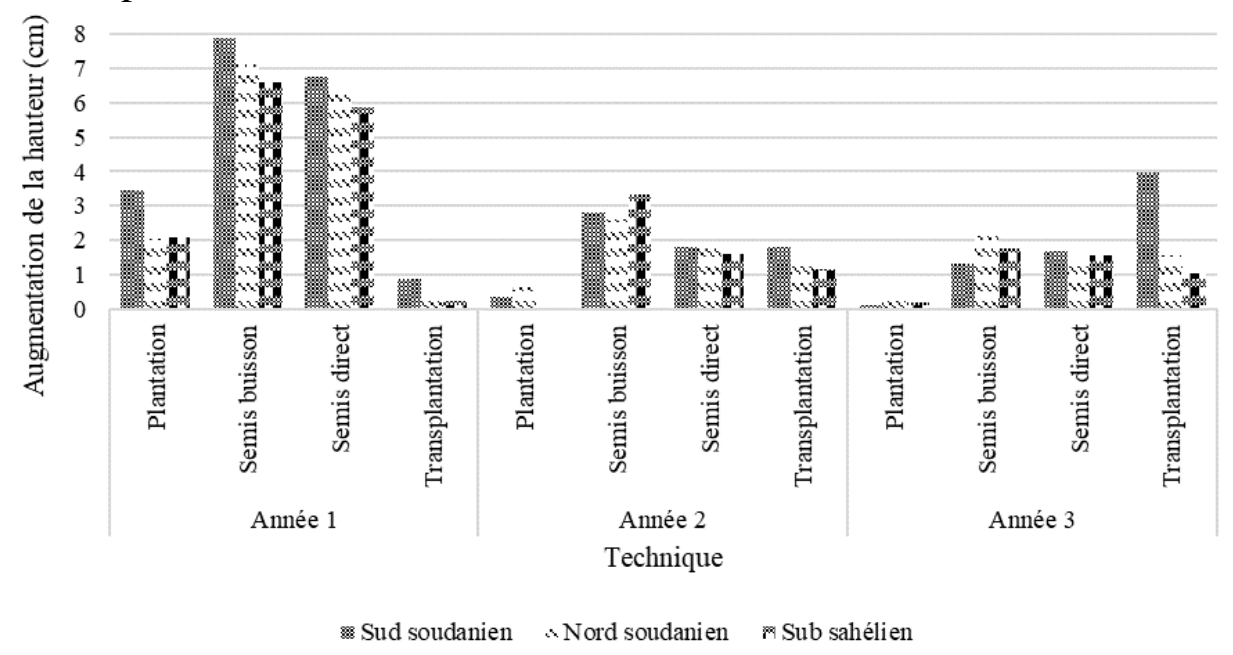

Figure 5. Croissance en hauteur des plantules par technique et par secteur phytogéographique

\section{Croissance verticale des plantules soumises à la RNA}

Les plants protégés et arrosés présentent une augmentation en hauteur qui décroît de 7,34 $\mathrm{cm}$ dans le secteur nord soudanien, $5,18 \mathrm{~cm}$ dans le secteur sud soudanien et de $2,01 \mathrm{~cm}$ dans le secteur sub sahélien. Les gains 
en hauteur plants protégés uniquement sont de $4,85 \mathrm{~cm}$ dans le secteur sud soudanien, $2,57 \mathrm{~cm}$ dans le secteur nord soudanien et $0,65 \mathrm{~cm}$ dans le secteur sub sahélien. Dans le cas des plants témoins, les augmentations de taille varient de $1,18 \mathrm{~cm}$ dans le secteur sud soudanien, $0,28 \mathrm{~cm}$ nord soudanien et $0,12 \mathrm{~cm}$ dans le secteur sub sahélien. Ainsi, la croissance en hauteur des juvéniles est plus élevée chez les plants protégés et arrosés que chez ceux ayant bénéficié de la protection uniquement. Ces derniers aussi sont en moyenne plus hauts que les témoins (figure 6).

Selon le secteur phytogéographique, la croissance en hauteur décroît du sud soudanien au sub sahélien. Dans le sud soudanien, l'arrosage n'a pas d'effet significatif sur la hauteur des plantules avec $X^{2}=0,011$ et $p=0,92$.

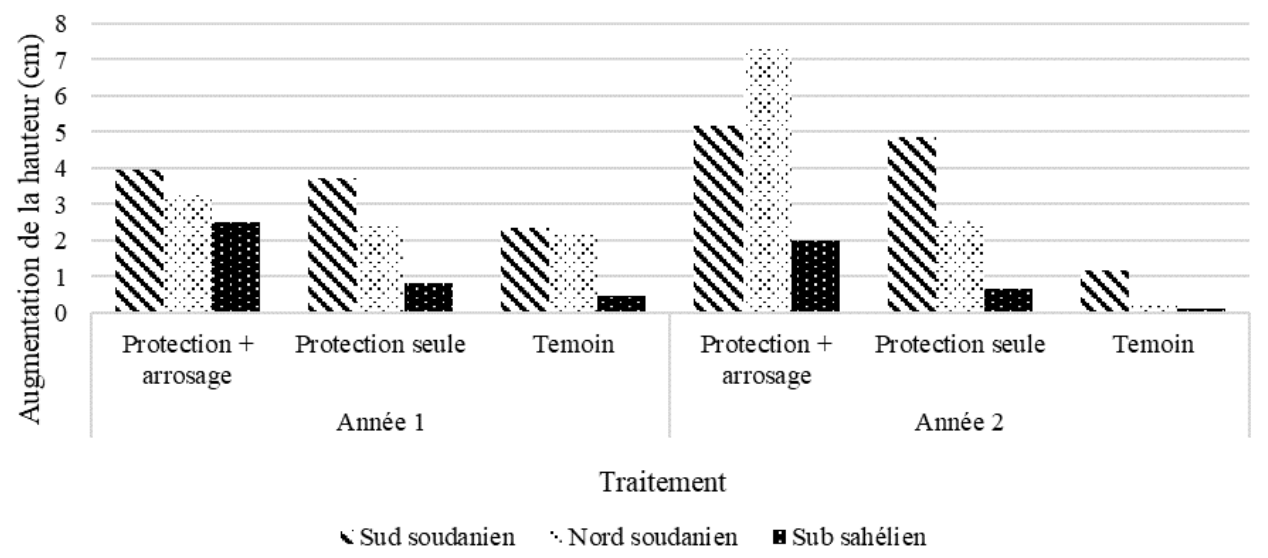

Figure 6. Croissance en hauteur des plantules par traitement et par secteur phytogéographique

Accroissement diamétrique des plantules issues de la plantation, du semis direct dans les buissons, du semis direct libre et de la transplantation

Les accroissements diamétriques des semis directs dans les buissons sont de 1,28 $\mathrm{mm}$ dans le secteur nord soudanien, 1,23 $\mathrm{mm}$ dans le secteur sud soudanien et de $0,71 \mathrm{~mm}$ dans le secteur sub sahélien. Les transplants présentent une augmentation diamétrique qui décroît du secteur sud soudanien $(1,42 \mathrm{~mm})$ au secteur nord soudanien $(0,98 \mathrm{~mm})$ et au secteur sub sahélien $(0,53 \mathrm{~mm})$. Dans le cas des semis directs libres, les augmentations de diamètre varient de $1,01 \mathrm{~mm}$ dans le secteur nord soudanien, $0,75 \mathrm{~mm}$ dans le secteur sud soudanien et $0,18 \mathrm{~mm}$ dans le secteur sub sahélien. Pour les plantules issues des plantations, les accroissements diamétriques diminuent de $0,75 \mathrm{~mm}$ dans le secteur sud soudanien, $0,40 \mathrm{~mm}$ dans le secteur nord soudanien et $0,28 \mathrm{~mm}$ dans le secteur sub sahélien (figure 7). Les diamètres des plantules ont relativement diminué plus rapidement en fonction du gradient phytogéographique sud-nord. Dans l'ensemble, les 
plantules issues des deux techniques de semis ont augmenté de diamètre plus vite que celles issues de plantations et de transferts de sauvageons. Cependant les transplants ont présenté une croissance marquée pendant que les plantules issues de plantations montraient une croissance relativement timide.

Les différences ne sont pas significatives entre la croissance diamétrique des semis directs dans les buissons et celles des semis directs libres avec $X^{2}=0,072$ et $p=0,84$. Il n'y a pas non plus de différence significative entre la croissance diamétrique des plantules issues de transplantation et celles issues de plantation avec $X^{2}=6,17$ et $p=0,95$.

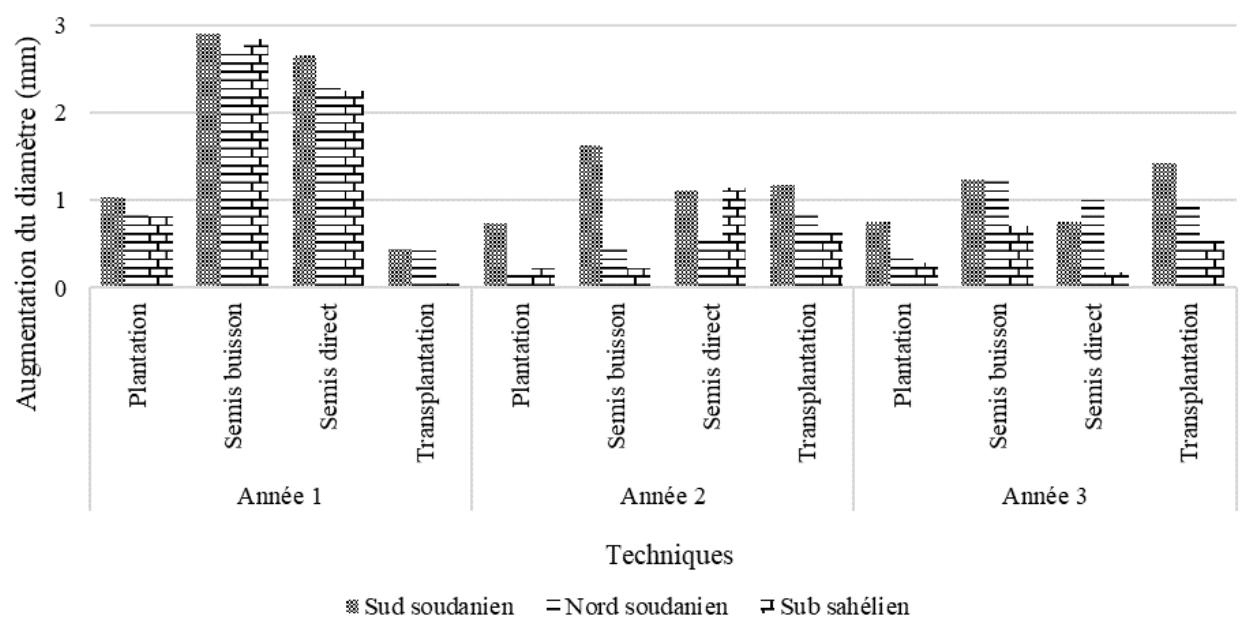

Figure 7. Accroissement diamétrique des plantules par technique et par secteur phytogéographique

\section{Accroissement diamétrique des plantules soumises la RNA}

Les accroissements diamétriques des plants protégés et arrosés sont les plus élevés soient de 3,28 mm dans le secteur sub sahélien, 1,07 mm dans le secteur sud soudanien et $1,06 \mathrm{~mm}$ dans le secteur nord soudanien. Les plants protégés uniquement présentent une augmentation diamétrique qui décroît du secteur sub sahélien $(1,62 \mathrm{~mm})$ au secteur nord soudanien $(0,61$ $\mathrm{mm}$ ) et au secteur sud soudanien $(0,41 \mathrm{~mm})$. Pour les plants témoins, les accroissements diamétriques diminuent de $0,74 \mathrm{~mm}$ dans le secteur nord soudanien à $0,51 \mathrm{~mm}$ dans le secteur sub sahélien et à $0,50 \mathrm{~mm}$ dans le secteur sud soudanien (figure 8). Quel que soit le traitement, les diamètres des plantules ont augmenté du secteur phytogéographique sud soudanien au secteur sub sahélien. Les plantules protégées et arrosées ont diamétralement crû plus vite que celles protégées uniquement qui à leur tour ont crû plus vite que les plants témoins. 
Dans les différents secteurs phytogéographiques, les différences ne sont pas significatives pour la croissance diamétrique d'un traitement à l'autre avec $\mathrm{X}^{2}=0,086$ et $\mathrm{p}=0,45$.

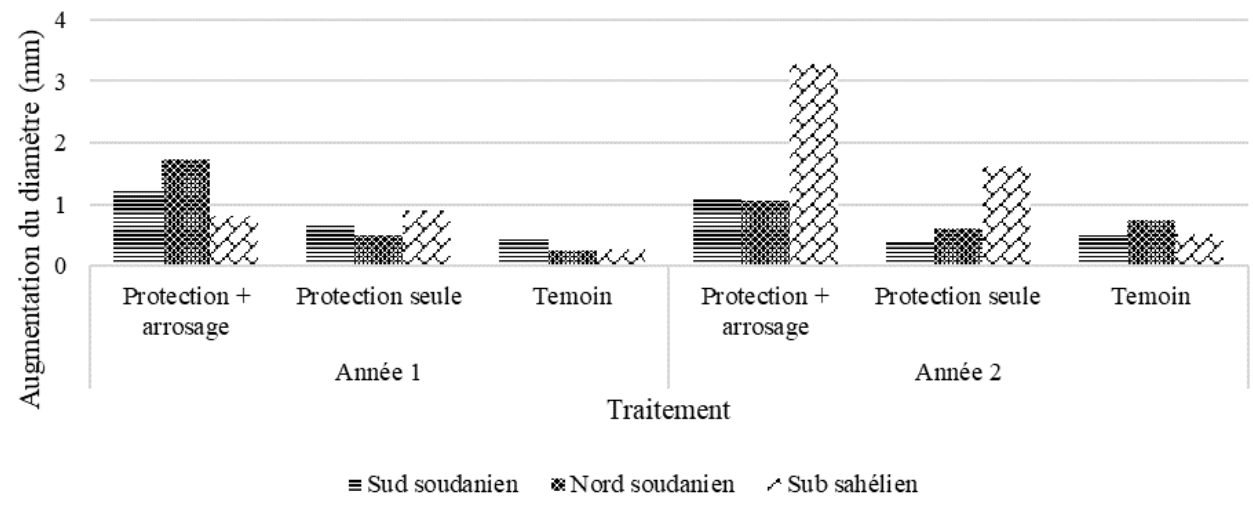

Figure 8. Accroissement diamétrique des plantules par traitement et par secteur phytogéographique

\section{Discussion}

\section{Induction de drageonnage et de pousses adventives}

Cette étude montre que le drageonnage n'est pas induit in situ chez le karité, par rupture ou scarification de la racine. Or, Belem et al. (2008) ont obtenu des drageons par scarification de racines de Bombax costatum Pelegr. et Vuillet. Aussi, Dourma et al. (2006) ont rapporté que chez Isoberlinia sp, le drageonnage peut être induit par des entailles sur les racines réalisées par la charrue. La réaction à l'induction du drageonnage est donc fonction des espèces. Le drageonnage serait alors une capacité intrinsèque à l'espèce, que le karité ne possèderait pas contrairement à ce que rapportent Bonkoungou (1987), Rouxel (2002), Harivel (2004) et Paba Salé (2004), d'autant plus que Ouoba et al. (2019) n'ont observé aucun drageon après des excavations de plantules de karité.

La pousse adventive constitue un appareil aérien rajeuni qui coexiste avec le pied principal que l'on pourrait couper, étant donné que sa relève est assurée. Les résultats obtenus montrent que les pousses adventives ne peuvent pas être induites par une scarification de la base du tronc du karité. Ces résultats sont en accord avec ceux de Bellefontaine (2005), qui rapporte que la formation de ces rejets basaux est spontanée, souvent sans aucun traumatisme de la tige-mère. A l'opposé, pour Blanc (2003) in Bellefontaine (2005), la pousse adventive apparaît lorsque la tige-mère devient sénescente et réduit sa croissance : il y a alors un transfert des ressources vers la plantefille accompagné à court terme de la disparition de la plante-mère. 


\section{Taux de survie}

Les taux de survie obtenus au cours de cette étude sont liés à la technique de régénération, mais aussi à la taille et à l'âge des plantules comme Kiltajima et Fenner (2000) 1'on rapporté. C'est ainsi que les taux de survie des sujets de la RNA sont les plus élevés quel que soit le secteur phytogéographique. En effet, ces plantules sont des sauvageons plus ou moins âgés déjà bien installés, donc plus résilientes que des plants élevés en pépinière. Les sujets de la RNA sont aussi plus résilients que des plants perturbés lors de l'opération de transplantation et que des semis directs. Aussi, lorsque les sujets de la RNA bénéficient d'un apport d'eau et d'une protection contre les dents et les sabots du bétail, ils fournissent les meilleurs taux de survie conformément aux résultats de cette étude. L'accompagnement de la régénération est donc bénéfique pour son maintien. Pour Bognounou (2009), le taux de survie varie aussi selon l'intensité, le régime des perturbations et la résilience spécifique de l'espèce suite à l'arrêt de perturbation. Ainsi, selon le gradient phytogéographique, le taux de survie des plantules a connu une augmentation du secteur sub sahélien au secteur sud soudanien où les facteurs mésologiques néfastes aux peuplements de karité sont en général moins exacerbés (Ouoba et al., 2018).

Le taux de germination de graines fraiches de karité rapporté par Picasso (1984) est de 90\%. En semis direct, le taux de levée baisse jusqu'à 40\% (Bonkoungou, 1987). A la suite de Thiombiano et al. (2016), cette étude attribue ce fait notamment à la récalcitrance des amandes de karité, à la consommation des graines par les rongeurs qui les déterrent et à une forte mortalité des plantules non entretenues.

Le semis direct est la technique qui nécessite le moins d'effort physique et de moyens financiers. Les buissons permettent d'augmenter le taux de survie des plantules. Ces dernières bénéficiant de la protection contre la dent et les sabots du bétail ainsi que de l'apport hydrique favorisé par la remontée d'eau grâce au système racinaire plus important du buisson et l'accumulation de litière au pied du buisson. Hormis la RNA, cette étude montre que la plantation est la méthode de régénération la plus fiable. La plantation est conseillée par Raebild et al. (2011b) car elle offre des taux de survie intéressants. Ainsi, des taux de $96 \%$ sont rapportés par Delolme (1947), qui a réalisé des plantations de karité en Côte d'Ivoire. Cependant selon Bonkoungou (1987) ainsi que Sallé et al. (1991), il faut entretenir les plantules en pépinière pendant au moins 2 ans, ce qui constitue une contrainte. En outre, un frein culturel majeur existe dans certaine localité où il est interdit de planter le karité au risque de mourir avant que l'espèce produise ses premiers fruits. La plantation est parfois interprétée comme signe d'appropriation d'une parcelle, raison pour laquelle seul le propriétaire terrien peut planter (Ouoba et al., 2018). 
Selon Sallé et al. (1991) la transplantation en motte du karité est possible conformément aux résultats auxquels cette étude est parvenue. Aussi, Delolme (1947) ainsi que Zerbo (1987) ont rapporté des taux de succès allant de $11 \%$ à $96 \%$. Les faibles taux de survie relevés seraient liés non seulement au stress que subit la plantule lors de l'opération mais aussi aux difficultés que le karité présente pour la reproduction végétative (bouturage et drageonnage).

\section{Croissance verticale et l'accroissement diamétrique}

L'accroissement annuel en diamètre de la tige des plantules est resté inférieur à $4 \mathrm{~mm}$ quelle que soit la technique de régénération durant l'étude. Cette valeur est proche de celle notée par Delolme (1947) sur le tronc du karité (soit de $4 \mathrm{~mm}$ en moyenne) et des $5 \mathrm{~mm}$ rapportés par Serpantié et al. (1996). Après douze mois de traitements favorables à la croissance et au développement des plantules de karité élevées en pépinière, Dianda et al. (2009) ont obtenu une hauteur moyenne de $11,9 \mathrm{~cm}$ et un diamètre moyen au collet de 2,6 $\mathrm{mm}$. Ces valeurs sont proches de celles auxquelles cette étude a abouti.

Les plantules issues de la plantation ont crû moins bien que celles issues de la transplantation. Ces résultats sont en accord avec ceux de Zerbo (1987) et Hall et al. (1996). Ce fait pourrait être expliqué par des difficultés d'accommodation au nouveau biotope. Il serait donc judicieux de prendre en compte la provenance des semences utilisées pour la production de plants en pépinière et même pour les restaurations du couvert végétal de façon générale.

\section{Conclusion}

Le taux de réussite des différentes techniques de régénération des parcs à karité étudiées dans cette activité augmente selon le secteur phytogéographique, du secteur sub sahélien au secteur sud soudanien. Aussi, la plantation et le semis direct dans les buissons peuvent être retenus pour densifier les parcs à karité, quel que soit le secteur phytogéographique du Burkina Faso. Cependant, lorsque les plantules naturellement établies sont bien positionnées hors de l'influence du houppier d'arbre adulte, la RNA constitue la technique la plus adéquate pour la régénération/restauration, car elle offre les meilleurs taux de survie et de croissance en plus d'être peu onéreuse. L'assistance fournie à une plantule lors de la RNA est également nécessaire aux plantules issues des autres techniques de régénération pour assurer leur protection et favoriser leur croissance. Pour ce qui est de la reproduction végétative, l'intervention de la biotechnologie à travers l'application de phytohormones pourrait stimuler la rhizogenèse dans le drageonnage. 


\section{Remerciements}

Les auteurs remercient la Fondation Internationale pour la Science (FIS), le Programme de Productivité Agricole en Afrique de l'Ouest (PPAAO/WAAPP) et l'Etat burkinabè à travers le Centre national de l'Information, de l'Orientation Scolaire et Professionnelle et des Bourses (CIOSPB) pour le financement de cette étude. Nous témoignons aussi notre gratitude envers les populations de Sobaka, Noumoudara, Kakoumana, Gonsé et Bouria ainsi qu'à l'interprofession de la Table Filière Karité (TFK) pour la coopération lors de la collecte de données.

\section{References :}

1. Assemblée Nationale du Burkina Faso. 2011. Loi Nº03-2011/AN du 05 avril 2011 portant code forestier.

2. APFNL, 2012. Etude sur la contribution des PFNL à l'économie nationale : cas de la filière fruit de l'arbre à karité. Rapport final, 82 p.

3. Baggnian I., Adamou Mahamane M., Toudou A. et Mahamane A., 2013. Impact des modes de gestion de la Régénération Naturelle Assistée des ligneux (RNA) sur la résilience des écosystèmes dans le Centre-Sud du Niger, Journal of Applied Biosciences, 71: 57425752. http://dx.doi.org/10.4314/jab.v71i1.9881

4. Belem B., Boussim I.J., Bellefontaine R. et Guinko S., 2008. Stimulation du drageonnage de Bombax costatum par blessure des racines au Burkina Faso. Bois et Forêts des Tropiques, 295 (1) 71-79.

5. Belem B., Kaguembega-mueller F., Bellefontaine R., Sorg J.P., Bloesch U. et Graf E., 2017. Assisted natural regeneration with fencing in the central and northern zone of Burkina. Tropicultura 35 (2): 73-86.

6. Bellefontaine R., 2005. Pour de nombreux ligneux, la reproduction sexuée n'est pas la seule voie : analyse de 875 cas - Texte introductif, tableau et bibliographie. "Sécheresse - revue électronique », $\mathrm{n}^{\circ} 3$.

7. Boffa J.M., 1999. Agroforestry Parklands in sub-Saharan Africa. FAO Conservation Guide 34. FAO, Rome.

8. Boffa J.M., 2015. Opportunities and challenges in the improvement of the shea (Vitellaria paradoxa) resource and its management. Occasional Paper 24. Nairobi: World Agroforestry Centre.

9. Bognounou F., 2009. Restauration écologique et gradient latitudinal : Utilisation, diversité et régénération de cinq espèces de Combretaceae au Burkina Faso. Thèse unique de Doctorat, Université de Ouagadougou, 139 p.

10. Bondé L., 2019. Distribution, production fruitière et potentiel socioéconomique de Tamarindus indica L. et de Vitellaria paradoxa 
C.F.Gaertn. au Burkina Faso. Thèse de doctorat ; Université Joseph Ki-Zerbo, BF. 182p.

11. Bonkoungou E.G., 1987. Monographie du Karité (Butyrospermum paradoxum Gaertn. f. Hepper), espèce agroforestière à usages multiples. IRBET / CNRST, 67 p.

12. Botoni E., Larwanou M. et Reij C., 2010. La régénération naturelle assistée (RNA) : une opportunité pour reverdir le Sahel et réduire la vulnérabilité des populations rurales. Le projet majeur africain de la Grande Muraille Verte : Concepts et mise en œuvre http://formadenvironnement.org/RNA_Botoni-Larwanou-Reij_2010.pdf

13. Burkina Faso, 2016. Plan National de Développement Economique et Social (PNDES). 97 p.

14. Delolme A., 1947. Etude du karité à la station agricole de Ferkéssédougou. Oléagineux 4, 186-200.

15. Dianda M., Bayala J., Diop T. et Ouédraogo J.S., 2009. Improving growth of shea butter tree (Vitellaria paradoxa C.F.Gaertn.) seedlings using mineral N, P and arbuscular mycorrhizal (AM) fungi. Biotechnologie, Agronomie, Société et Environnement 13(1), 93-102.

16. Dianda M., Ouedraogo S.J. et DIOP A.T., 2010. Variation de la réponse à l'endomycorhization en pépinière des plants issus de deux semenciers de karité au Burkina Faso. International Journal of Biological and Chemical Sciences, 4(5): 1742-1752.

17. Dourma M., Guelly K.A., Kokou K., Batawila K., Wala K., Bellefontaine R. et Akpagana K., 2006. Multiplication par drageonnage d'Isoberlinia doka et I. tomentosa au sein des formations arborées du Nord-Togo. Bois et Forêts des Tropiques, 2006, $\mathrm{N}^{\circ} 289$ (3), 49-57.

18. Gaisberger H., Kindt R., Loo J., Schmidt M., Bognounou F., Da S.S., Diallo O.B., Ganaba S., Gnoumou A., Lompo D., Lykke A.M., Mbayngone E., Nacoulma B.M.I., Ouedraogo M., Ouédraogo O., Parkouda C., Porembski S., Savadogo P., Thiombiano A., Zerbo G. et Vinceti B., 2017. Spatially explicit multi-threat assessment of food tree species in Burkina Faso: A fine-scale approach. Plos One, 12, e0184457. https://doi.org/10.1371/journal.pone.0184457

19. Ganaba S, Ouadba JM, Bognounou O, 2002. Utilisation des ressources végétales spontanées comme complément alimentaire en région sahélienne du Burkina Faso. Annales de Botanique de l'Afrique de l'Ouest 2 : 101-11.

20. Hall J.B., Aebischer D.P., Tomlinson H.F., Osei-Amaning E. et Hindle J.R., 1996. Vitellaria paradoxa C.F. Gaertn. A monograph. School of Agricultural and Forest Sciences. University of Wales Bangor U.K. 105p. 
21. Hardwick K., Healey J., Elliott S., Garwood N. et Anusarnsunthorn V., 1997. Understanding and assisting natural regeneration processes in degraded seasonal evergreen forests in northern Thailand. Forest Ecology and Management 99: 203-214.

22. Harivel A., 2004. Etude préalable à l'aménagement de la forêt villageoise de Dioroum. Evaluation de la régénération de huit espèces ligneuses en région sahélo-soudanienne : induction du drageonnage, bouturage de segment de racine, marcottage aérien (Burkina Faso), Mémoire de DESS, Paris XII, 74p.

23. Honu Y.A.K. et Dang Q.L., 2002. Spatial distribution and species composition of tree seeds and seedlings under the canopy of the shrub, Chromolaena odorata Linn., in Ghana. Forest Ecology and Management 164: 185-196.

24. INSD, 2018. Annuaire statistique 2017. Décembre 2018, 383p.

25. Kaboré S.A., Bastide B., Traoré S. et Boussim J.I., 2012. Dynamique du karité, Vitellaria paradoxa, dans les systèmes agraires du Burkina Faso. Bois et Forêts des Tropiques, 2012, n³13 (3), 47-59.

26. Kiltajima K. et Fenner M., 2000. Ecology of Seedling Regeneration. In Fenner M. ed. The Ecology of Regeneration of Plant Communities: CABI Publishing Wallingford, 331-359.

27. Lafleur M., 2008. Recherches et documentation des meilleures pratiques pour la gestion durable des parcs à karité en Afrique de l'Ouest. Rapport de stage OCI, $110 \mathrm{p}$.

28. Larwanou M., Abdoulaye M. et Reij C., 2006. Etude de la Régénération Naturelle Assistée dans la Région de Zinder (Niger) une Première Exploration d'un Phénomène Spectaculaire. United States Agency for International Development, USAID/EGAT, https://www.formadenvironnement.org/RNA_Zinder_USAI D, 56 p.

29. Lawali S., Diouf A., Morou B., Abdou Kona K., Saidou L., Guero C. et Mahamane A., 2018. Régénération Naturelle Assistée (RNA) : outil d'adaptation et résilience des ménages ruraux d'Aguié au Niger. International Journal of Biological and Chemical Sciences 12(1): 7589.

30. Marou Zarafi A., Abasse A.T., Bokar M., Niang A. et Traore C.O., 2002. Analyse de l'adoption de la régénération naturelle assistée dans la région de Maradi au Niger. 2e Atelier régional sur les aspects socio-économiques de l'agroforesterie au sahel. Bamako, 4 - 6 mars 2002.

31. Naughton C.C., Lovett P.N. et Mihelcic J.R., 2015. Land suitability modeling of shea (Vitellaria paradoxa) distribution across subSaharan Africa. Applied Geography, 58, 217-227. http://dx.doi.org/10.1016/j.apgeog.2015.02.007. 
32. Ouédraogo P., Bationo B.A., Sanou J., Traoré S., Barry S., Dayamba S.D., Bayala J., Ouédraogo M., Soeters S. et Thiombiano A., 2017. Uses and vulnerability of ligneous species exploited by local population of northern Burkina Faso in their adaptation strategies to changing environments. Agriculture \& Food Security, 6, 1-16. doi 10.1186/s40066-017-0090-z.

33. Ouoba Y.H., Bastide B., Coulibaly-Lingani P., Kaboré S.A. et Boussim I.J., 2018. Connaissances et perceptions des producteurs sur la gestion des parcs à Vitellaria paradoxa C. F. Gaertn. (karité) au Burkina Faso. International Journal of Biological and Chemical Sciences 12(6) : 2766-2783. DOI : https://dx.doi.org/10.4314/ijbcs.v12i6.23.

34. Ouoba Y.H., Bastide B., Kaboré S.A., Yaméogo/Gamene C.S. et Boussim I.J., 2019. Modes de régénération naturelle du karité, Vitellaria paradoxa C. F. Gaertn. dans les parcs agroforestiers au Burkina Faso. Vol. 38, $\mathrm{n}^{\circ}$ 2, Science et technique, Sciences naturelles et appliquées, 191-205.

35. Paba Salé D.L., 2004. Contribution à l'étude de la propagation végétative naturelle en zone soudano-guinéenne du Cameroun : caractérisation du drageonnage d'Albizia zygia et Allophylus africanus dans la localité de Dang (Ngaoundéré). Mémoire de Maîtrise, Biologie et Physiologie Végétales, Faculté des Sciences, Université de Ngaoundéré, Cameroun, 24 p.

36. Peltier R., Forkong C.N., Ntoupka M., Manlay R., Henry M. et Morillon V., 2007. Évaluation du stock de carbone et de la productivité en bois d'un parc à karités du Nord-Cameroun. Bois et Forêts des Tropiques, 294 : 39-50.

37. Picasso C., 1984. Synthèse des résultats acquis en matière de recherche sur le Karité au Burkina Faso de 1950 à 1958. Institut de Recherches pour les Huiles et Oléagineux, $45 \mathrm{p}$.

38. Raebild A., Larsen A.S., Jensen J.S., Ouédraogo M., De Groote S., Van Damme P., Bayala J., Diallo B.O., Sanou H., Kalinganire A., Kjaer E.D., 2011a. Advances in domestication of indigenous fruit trees in the West African Sahel. New Forests 41 :297-315. DOI 10.1007/s11056-010-9237-5

39. Raebild A., Hansen U.B. et Kambou S., 2011b. Regeneration of Vitellaria paradoxa and Parkia biglobosa in a parkland in Southern Burkina Faso. Agroforestry Systems 11p. DOI 10.1007/s10457-0119397-0.

40. Rouxel C., 2002. De la biodiversité arborée au sein de terroirs de la zone semi-aride ouest-africaine : cas des parcs agroforestiers du village de M'Pébougou Sokala (région de Ségou, Mali). Mémoire 
DESS : Gestion des systèmes agro-sylvo-pastoraux en zones tropicales. Université Paris XII, Paris, 72 p.

41. Sallé G., Boussim I.J., Raynal-Roques A. et Brunck F., 1991. Le karité une richesse potentielle. Perspectives de recherches pour améliorer sa productivité. Revue Bois et Forêts des Tropiques, ${ }^{\circ}$ 228, 11-23.

42. Sanou H., Kambou S., Teklehaimanot Z., Dembele M., Yossi H., Sina S., Djingdia L. et Bouvet J.-M. , 2004. Vegetative propagation of Vitellaria paradoxa by grafting. Agroforestry Systems 60:93-99.

43. Serpantié G., Bayala J., Helmfrid S. et Lamien N., 1996. Pratiques et enjeux de la culture du karité (Butyrospermum paradoxum Gaertn. f. Hepper) dans l'Ouest du Burkina Faso. In : FLORET CHRISTIAN (ED.). La jachère, lieu de production. Dakar : ORSTOM, 59-72 multigr. La Jachère, Lieu de Production : Atelier, Bobo-Dioulasso (BKF), 1996/10/02-04.

44. Shono K., Cadaweng E.A., Patrick B. et Durst P.B., 2007. Application of Assisted Natural Regeneration to Restore Degraded Tropical Forestlands. Restoration Ecology 15 (4): 620-626.

45. Thiombiano A., Bonkoungou E.G., Sawadogo L, Ouadba J.M., Boussim J.I., Ganaba S., Diallo O.B., Sina S., Ouédraogo K., Kaboré C., Coulibaly/Lingani P., Zida D. et Soulama S., 2016. Etat des peuplements et du développement des technologies pour une meilleure productivité du karité au Burkina Faso. CORAF/INERA, Ouagadougou, 76p.

46. Thiombiano D.N.E., Lamien N., Dibong S.D. et Boussim I.J., 2010. Etat des peuplements des espèces ligneuses de soudure des communes rurales de Pobé-Mengao et de Nobéré (Burkina Faso) Journal of Animal \& Plant Sciences, 2010. Vol. 9, Issue 1 : 11041116. ISSN 2071 - 7024.

47. Zerbo J.L., 1987. Expérimentation de technique de production de plants d'arbres utilisés en agroforesterie traditionnelle : cas du karité Butyrospermum paradoxum (Gaertner F.) Hepper. Mém. de Fin d'Etudes : Développement Rural : Eaux et Forêts, IDR, Université de Ouagadougou,75p. 